DOI: $10.17516 / 1999-494 X-0213$

УДК $517.442+519.677$

\title{
Assessment of Hybrid Method on Investigation of Dynamic Behaviour \\ of Isotropic Rectangular Plates Resting \\ on Two-Parameters Foundation
}

\author{
Saheed Salawu and Gbeminiyi Sobamowo* \\ University of Lagos \\ Akoka, Nigeria
}

Received 07.04.2019, received in revised form 01.11.2019, accepted 21.01.2020

\begin{abstract}
Dynamic behaviour of isotropic rectangular plate resting on two-parameter foundation is investigated. The governing partial differential equation is transformed to ordinary differential equation due to Galerkin method of separation. The hybrid method of Laplace transform and variation parameters method is used to analyze the ordinary differential equation. Introduction of exact method helps in fast convergence of the results. Obtained analytical solutions are compared with existing literature and confirmed as accurate. They are used to examine the effect of controlling parameters on the plate natural frequencies. Due to obtained results it is obvious that, the increase of both elastic foundation parameter and aspect ratio results in increasing the natural frequency. The solution is found immediately by means of a few iterations.
\end{abstract}

Keywords: dynamic analysis, natural frequency, deflection, Winkler and Pasternak, Laplace and variation parameters method.

Citation: Salawu S., Sobamowo G. Assessment of hybrid method on investigation of dynamic behaviour of isotropic rectangular plates resting on two-parameters foundation, J. Sib. Fed. Univ. Eng. \& Technol., 2020, 13(2), 162-174. DOI: 10.17516/1999494X-0213

(c) Siberian Federal University. All rights reserved

This work is licensed under a Creative Commons Attribution-NonCommercial 4.0 International License (CC BY-NC 4.0).

* Corresponding author E-mail address: safolu@gmail.com, mikegbeniyi@gmail.com 


\title{
Оценка гибридного метода исследования
}

\author{
динамического поведения изотропных
}

прямоугольных пластин,

опирающихся на двухпараметрическое основание

\author{
Сахид Салаву, Гбеминийи Собамово \\ Университет Лагоса \\ Нигерия, Акока
}

\begin{abstract}
Аннотация. Исследовано динамическое поведение изотропной прямоугольной пластины, опирающейся на двухпараметрическое основание. Основное дифференциальное уравнение в частных производных преобразуется в обыкновенное дифференциальное уравнение с использованием метода разделения Галеркина. Для анализа обыкновенного дифференциального уравнения применен гибридный метод преобразования Лапласа и параметров вариации. Введение точного метода помогает в быстрой конвергенции результатов. Полученные аналитические решения сравниваются с существующей литературой и подтверждаются с хорошей точностью. Их используют для изучения влияния управляющих параметров на собственные частоты пластины. Из полученных результатов видно, что рост параметров упругого основания и соотношения сторон увеличивает собственную частоту. Решение находят быстро с несколькими итерациями.
\end{abstract}

Ключевые слова: динамический анализ, собственная частота, отклонение, Винклер и Пастернак, метод параметров Лапласа и вариации.

Цитирование: Салаву, С. Оценка гибридного метода исследования динамического поведения изотропных прямоугольных пластин, опирающихся на двухпараметрическое основание / С. Салаву, Г. Собамово // Журн. Сиб. федер. ун-та. Техника и технологии, 2020. 13(2). С. 162-174. DOI: 10.17516/1999-494X-0213

\section{Introduction}

Recently the significant and wide application of thin rectangular plates in mechanical, civil, marine, naval, nuclear and aeronautic engineering, have increased various research interests to the study of dynamic analysis of thin rectangular plate. In the study of free vibration of rectangular plate of varying thickness Sundara et al. [1] applied finite element method. In another work, Cheung and Kong [2] used finite element method for analyzing dynamic response of rectangular plate of varying thickness. However, research into plate resting on two-parameter elastic foundation has gained much attention among researchers based on the various publications available due to the subject, importance and application in various branches of engineering. Singh and Adhikari [3] adopted finite element method in determining the dynamic response of functionally graded plate on two-parameter foundation. Finite element method is applied to analyze the vibration of rectangular plates resting on elastic foundation by Karasin [4]. In another study, Zenkour and Radwar [5] used hyperbolic shear deformation in studying of functionally graded plate resting on Winkler and Pasternak foundation.

Based on previous studies on vibration, it is realized that sorting out vibration problem is difficult to handle due to inherent non-trivial solution. Meanwhile, the most adequate method of solution for nonlinear problem is numerical, but this one has restrictions and limitations. The numerical method is not able to provide the closed form solutions. Exact analytical approximate 
method is also limited to handle linear problem. While semi - analytical method is able to correct the limitation in both methods. However, to obtain closed form solution, Vgor and Eisen [6] adopted semi-analytic Kantorovich method for determining free vibration response of varying thickness rectangular plate. In a further study, Mustapha and Ajetumobi [7] utilized variation iteration method for solving some problems in vibration. Also, Attarnejad et al. [8] applied differential transform method for analyzing Timoshenko beam on two-parameter foundation. Variation of parameter method (VPM) [9-12] is a very reliable method of getting closed form solution without the restriction of small parameters in Homotopy perturbation method, conversion of governing equation to recursive relation in differential transform and calculating the langrage multiplier in variation of iteration method. By means of a few iterations the solution has been found. Combining Laplace transform and Variation of parameter methods means that, the effectiveness of the method increases further because of the combination of exact method for linear part of the equation and VPM for the other part of the governing equation.

After detail study of the literature review, the authors found out that no attention has been drawn to application of hybrid VPM to investigate the dynamic analysis of isotropic rectangular plates resting on Winkler and Pasternak foundations. Therefore, the present study focuses on the application of hybrid VPM dynamic investigation of isotropic thin rectangular plate resting on two-parameter nonlinear foundation. Obtained results are used for parametric investigations.

\section{Problem formulation and mathematical analysis}

Rectangular plate of uniform thickness and uniform density is considered. The plate is resting on combine linear Winkler and nonlinear Pasternak foundation under different edge conditions as shown in Fig. 1.

The following assumptions are made for the development of the governing equation [13]:

1) Plate is a member whose middle surface lies in plane.

2) Thickness of plate is smaller compared to the other dimensions.

3) Plate is of constant thickness.

4) Thickness is normal to the mid-surface plane.

The governing equation for thin isotropic rectangular plate as reported by [14] is;

$$
D\left(\frac{\partial^{4} w(x, y, \mathrm{t})}{\partial x^{4}}+2 \frac{\partial^{4} w(x, y, \mathrm{t})}{\partial x^{2} \partial y^{2}}+\frac{\partial^{4} w(x, y, \mathrm{t})}{\partial y^{4}}\right)+\rho h \frac{\partial^{2} w(x, y, \mathrm{t})}{\partial t^{2}}+k_{w} w(x, y, \mathrm{t})+k_{p} w^{3}(x, y, \mathrm{t})=0,
$$

where $D$ is the flexural rigidity $\frac{E h^{3}}{12\left(1-v^{2}\right)}, E$ is the modulus of elasticity, $h$ is the plate thickness, $v$ is the Poisson's ratio, Plate is resting on $k_{w}, k_{p}$ Winkler foundation and Pasternak foundation respectively and $\rho$ is the density. Offering a further general solution, the following dimensionless variables are defined:

$$
W=\frac{w}{w_{\max }}, X=\frac{x}{a}, Y=\frac{y}{b} .
$$

For free vibration, the solution of Eq. (1) can be presented in Kantorovich type approximation

$$
w(x, y, t)=w(x, y) e^{i \omega t} .
$$




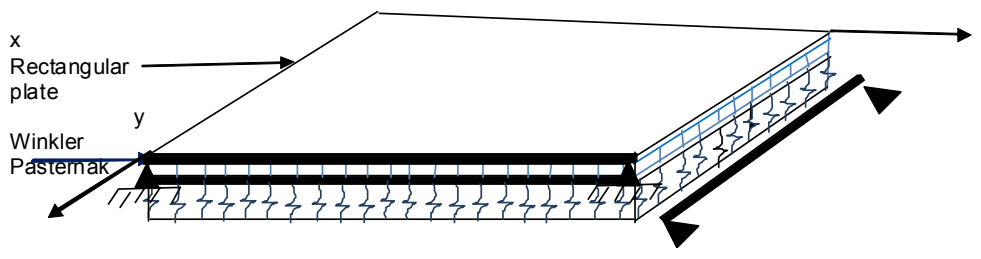

Fig. 1. Plate resting on two-parameter foundation

$$
\begin{aligned}
& \text { Also, } \Omega^{2}=\frac{a^{4} \rho h}{D} \omega^{2}, k_{w}=\frac{a^{4} k_{w}}{D}, k_{p}=\frac{a^{4} k_{p} w_{\max }^{2}}{D}, \\
& \frac{\partial^{4} W(x, y)}{\partial X^{4}}+2 \lambda^{2} \frac{\partial^{4} W(x, y)}{\partial X^{2} \partial Y^{2}}+\lambda^{4} \frac{\partial^{4} W(x, y)}{\partial Y^{4}}-\Omega^{2} W(x, y)+k_{w} W(x, y)+k_{p} W^{3}(x, y)=0 .
\end{aligned}
$$

Assuming the two opposite edges of Fig. 1, $Y=0$ and $Y=1$ to be simply supported, deflection function can be represented as follows

$$
W=W(X) \sin (m \pi Y) \text {. }
$$

Substituting the derivative of Eq. (6) into governing differential Eq. (5) gives:

$$
\frac{d^{4} W(X)}{d X^{4}}-2 \lambda^{2} m^{2} \pi^{2} \frac{d^{2} W(X)}{d X^{2}}-\left(\Omega^{2}-k_{w}-\lambda^{4} m^{4} \pi^{4}\right) W(X)+k_{p} W^{3}(X)=0 .
$$

\subsection{Boundary Conditions}

Three boundary conditions combinations are considered at $X=0$ and $X=l$. For brevity sake, notations are adopted in identifying the edge conditions: Simply supported and Clamped edge (SC), Simply supported and Simply Supported edge (SS) and Simply supported and Free edge conditions (SF).

Clamped edge: $W=\frac{d W}{d X}=0$.

Simply Supported edge: $W=\frac{d^{2} W}{d X^{2}}-v\left(m^{2} \pi^{2} \lambda^{2}\right) W=0$.

Free edge: $\frac{d^{2} W}{d X^{2}}-v\left(m^{2} \pi^{2} \lambda^{2}\right) W=0, \quad \frac{d^{3} W}{d X^{3}}-(2-v)\left(m^{2} \pi^{2} \lambda^{2}\right) \frac{d W}{d X}=0$.

\section{Method of solution: laplace transform and variation parameter method}

\subsection{Basic ideal of Laplace transform}

If $f(t)$ is a function of a variable $t . \mathcal{L}\{F(t)\}$ and is defined by the integral:

$$
\mathscr{L}\{F(t)\}=f(s)=\int_{0}^{\infty} e^{-s t} F(t) d t
$$

Some of the properties used in this study include:

- $\mathscr{L}\{1\}=\frac{1}{s}(s>0)$, 
- $\mathcal{L}\left\{t^{n}\right\}=\frac{n !}{s^{n+1}}(s>0)$

- $\mathcal{L}\left\{F^{(n)}(t)\right\}=s^{n} f(s)-s^{n-1} F(0)-s^{n-2} F^{\prime}(0)-\cdots F^{(n-1)}(0)$,

where $F^{(n)}(t)$ represents the $n$-th derivative of $F(t)$ and $\mathscr{L}\{F(t)\}=f(s)$. If Laplace transform of $F(t)$ is $f(s)$, then the inverse Laplace transform of $f(s)$ is expressed by $F(t)=\mathscr{L}^{-1}\{f(s)\}$, where $\mathscr{L}^{-1}$ is called inverse Laplace operator.

The inverse Laplace of Eqs. (12) and (13) are:

- $1=\mathscr{L}^{-1}\left(\frac{1}{s}\right)$,

- $t^{n}=\mathscr{L}^{-1}\left(\frac{n !}{s^{n+1}}\right)$.

\subsection{Basic ideal variation of parameter method}

To demonstrate the principle of variation parameter method (VPM), this nonlinear differential term is considered,

$$
\frac{d^{m} w}{d x^{m}}+R(x)+N(x)=f(x)
$$

With this initial condition,

$$
w^{(k)}(0)=w_{0},
$$

where $w=w(x), R$ represent the linear operator, $N$ is the nonlinear operator, $f(x)$ represent the nonhomogenous term, $\frac{d^{m} w}{d x^{m}}$ is the highest order derivative.

$$
L w(x)+R w(x)+N w(x)=g,
$$

$L$ denotes highest linear operator, $R$ the remaining linear operators aside the highest linear, $N$ is the nonlinear operator.

$$
\begin{aligned}
& w_{n+1}(x)=w_{n}(x)+\int_{0}^{\xi} \lambda(x, \xi)\left(R\left(w_{n}\right) \xi+N\left(w_{n}\right) \xi-f(\xi)\right) d \xi \\
& w_{n}(x)=w(0)+x w^{\prime}(0)+\frac{x^{2}}{2 !} w^{\prime \prime}(0)+\frac{x^{3}}{3 !} w^{\prime \prime \prime}(0)+\frac{x^{n-1}}{n-1 !} w n^{(n-1)}(0),
\end{aligned}
$$

$\lambda$ is a general Wronskian technique $\lambda=\sum_{i}^{m} \frac{(-1)^{i-1} s^{i-1} x^{m-1}}{(i-1) !(m-i) !}$, and $\mathrm{n}$ represents $n t h$ approximation, $w_{n}(x)$ represent the solution of the linear operator. $m$ in the Wronskian represent the order of the derivative. Having obtained the initial iteration $w_{n}(x)$ and the Wronskian, subsequent iterations is performed using Eq. (20). 


\subsection{Basic Concept and the Procedure}

\section{of Laplace Variation Parameter Method}

This approach helps in the rate of convergence, once the linear part of the operator is solved using exact method of the solution. Laplace transform of governing equation is taking as;

$$
\begin{aligned}
& w_{n+1}(x)=w_{n}(s)+\int_{0}^{\xi} \lambda(x, \xi)\left(L\left(w_{n}\right) \xi+R\left(w_{n}\right) \xi+N\left(w_{n}\right) \xi-f(\xi)\right) d \xi, \\
& \mathcal{L}\left[w_{n+1}(x)\right]=\mathcal{L}\left[w_{n}(s)\right]+\mathcal{L}[\lambda(x)] \mathcal{L}\left[L\left(w_{n}\right)\right]+\mathcal{L}\left[R\left(w_{n}\right)+N\left(w_{n}\right)-f(x)\right], \\
& \bar{w}_{n+1}(s)=\bar{w}_{n}(s)+\bar{\lambda}(s)\left\{s^{m} \bar{w}_{n}(s)-s^{m-1} w(0)-\ldots-w^{(m-1)}(0)+\mathcal{L}\left[R\left(\bar{w}_{n}\right)+N\left(\bar{w}_{n}\right)-\bar{f}(x)\right]\right\} .
\end{aligned}
$$

Eq. (24) is make stationary with $w_{n}$

$$
\frac{\delta}{\delta w_{n}} \bar{w}_{n+1}(s)=\frac{\delta}{\delta w_{n}} \bar{w}_{n}(s)+\frac{\delta}{\delta w_{n}} \bar{\lambda}(s)\left(s^{m} \bar{w}_{n}(s)\right)
$$

Apply restricted variation $\delta w_{n}=0$

$$
\left[\delta \bar{w}_{n+1}(s)\right]=\left[\delta \bar{w}_{n}(s)\right]+\delta[\bar{\lambda}(s)]\left[s^{m} \bar{w}_{n}(s)\right] .
$$

The extremum condition of $\bar{w}_{n+1}(s)$ need that, $\delta \bar{w}_{n+1}(s)=0$

$$
\begin{aligned}
& 0=\left[\delta \bar{w}_{n}(s)\right]+\delta[\bar{\lambda}(s)]\left[s^{m} \bar{w}_{n}(s)\right], \\
& \bar{\lambda}(s)=-\frac{1}{s^{m}} .
\end{aligned}
$$

Subsequent iterations obtained through inverse Laplace transform of Eq. (24);

$$
\begin{aligned}
& w_{n+1}(x)=w_{n}(x)-\mathcal{L}^{-1}\left[-\frac{1}{s^{m}}\left\{s^{m} \bar{w}_{n}(s)-s^{m-1} w(0)-\ldots-w^{(m-1)}(0)+\mathcal{L}\left[R\left(\bar{w}_{n}\right)+N\left(\bar{w}_{n}\right)-\bar{f}(x)\right]\right\},\right. \\
& \Rightarrow \mathcal{L}^{-1}\left[\frac{1}{s^{m}}\left\{s^{m-1} w(0)+\ldots+w^{(m-1)}(0)\right\}\right]+\mathcal{L}^{-1}\left[\frac{1}{s^{m}} \mathcal{L}\left[R\left(\bar{w}_{n}\right)+N\left(\bar{w}_{n}\right)-\bar{f}(x)\right]\right] \\
& w_{0}=\mathcal{L}^{-1}\left[\frac{1}{s^{m}}\left\{s^{m-1} w(0)+\ldots+w^{(m-1)}(0)\right\}\right] \\
& w_{n+1}(x) \Rightarrow+\mathcal{L}^{-1}\left[\frac{1}{s^{m}} \mathcal{L}\left[R\left(\bar{w}_{n}\right)+N\left(\bar{w}_{n}\right)-\bar{f}(x)\right]\right] .
\end{aligned}
$$

\subsection{Application of LH-VPM on the system governing equation}

Based on the basic rule of LH-VPM, the governing equation may be analyzed as:

$$
\begin{aligned}
& \frac{d^{4} W(x)}{d X^{4}}-2 m^{2} \pi^{2} \lambda^{2} \frac{d^{2} W(x)}{d X^{2}}-\left(\Omega^{2}-m^{4} \pi^{4} \lambda^{4}-k_{w}\right) W(x)-k_{p} W^{3}(x)=0, \\
& \frac{d^{n} W}{d X^{n}}=s^{n} \mathcal{L}[\bar{W}]-s^{n-1} W(0)-s^{n-2} W^{\prime}(0)-s^{n-3} W^{\prime \prime}(0)-\cdots \cdots W^{n-1}(0), \\
& \mathcal{L}[L W(x, y)]+\mathcal{L}[R W(x, y)]+\mathcal{L}[N W(x, y)]=\mathcal{L}[f(x, y)], \\
& -167-
\end{aligned}
$$




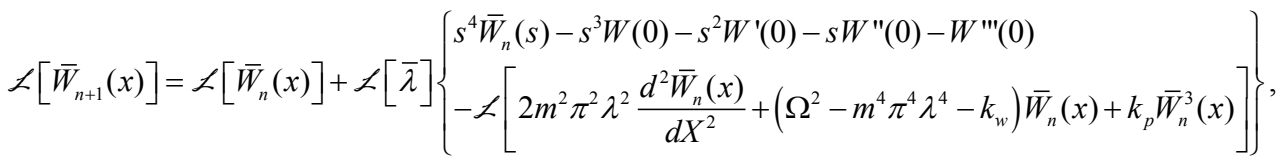

$$
\begin{aligned}
& \bar{W}_{n+1}(s)=\bar{W}_{n}(s)+\bar{\lambda}(s)\left[\begin{array}{l}
s^{4} \bar{W}_{n}(s)-s^{3} W(0)-s^{2} W^{\prime}(0)-s W^{\prime \prime}(0)-W^{\prime \prime \prime}(0) \\
-\mathcal{L}\left[2 m^{2} \pi^{2} \lambda^{2} \frac{d^{2} \bar{W}_{n}(x)}{d X^{2}}+\left(\Omega^{2}-m^{4} \pi^{4} \lambda^{4}-k_{w}\right) \bar{W}_{n}(x)+k_{p} \bar{W}_{n}^{3}(x)\right]
\end{array}\right] .
\end{aligned}
$$

Laplace Transform of Boundary condition

$$
\begin{aligned}
& \bar{W}(0)=\bar{W}^{\prime \prime}(0)=0, \\
& \bar{\lambda}(s)=-\frac{1}{s^{4}},
\end{aligned}
$$

Taking the inverse Laplace Transform let the unknown be $\alpha \Rightarrow W^{\prime}(0)$ and $\beta \Rightarrow W^{\prime \prime \prime}(0)$

$$
\begin{aligned}
& W_{n+1}(x)=-\swarrow^{-1} \frac{1}{s^{4}}\left[-s^{2} \alpha-\beta\right]-\mathcal{L}^{-1}\left\{\frac{1}{s^{4}}\left[\mathcal{L}\left[2 m^{2} \pi^{2} \lambda^{2} \frac{d^{2} \bar{W}_{n}(x)}{d X^{2}}+\left(\Omega^{2}-m^{4} \pi^{4} \lambda^{4}-k_{w}\right) \bar{W}_{n}(x)+k_{p} \bar{W}_{n}^{3}(x)\right]\right]\right\}, \\
& W_{0}(x)=\frac{1}{6} x\left(\beta x^{2}+6 \alpha\right) \text {, } \\
& W_{n+1}(x)=-\mathcal{L}^{-1}\left\{\frac{1}{s^{4}}\left[\mathcal{L}\left[2 m^{2} \pi^{2} \lambda^{2} \frac{d^{2} \bar{W}_{n}(x)}{d X^{2}}+\left(\Omega^{2}-m^{4} \pi^{4} \lambda^{4}-k_{w}\right) \bar{W}_{n}(x)+k_{p} \bar{W}_{n}^{3}(x)\right]\right]\right\}, \\
& W_{1}(x)=-\mathcal{L}^{-1}\left\{\frac{1}{s^{4}}\left[\mathcal{L}\left[2 m^{2} \pi^{2} \lambda^{2} \frac{d^{2} \bar{W}_{0}(x)}{d X^{2}}+\left(\Omega^{2}-m^{4} \pi^{4} \lambda^{4}-k_{w}\right) \bar{W}_{0}(x)+k_{p} \bar{W}_{0}^{3}(x)\right]\right]\right\} \text {, } \\
& W_{1}(x)=\mathcal{L}^{-1}\left\{\frac{1}{s^{4}}\left[\mathcal{L}\left[\frac{\left(-\pi^{4} \lambda^{4} m^{4}+\Omega^{2}-k_{w}\right)\left(\alpha s^{2}+\beta\right)}{s^{4}}+\frac{k_{P}\left(\alpha s^{2}+\beta\right)^{3}}{s^{12}}\right]\right]\right\} \text {, } \\
& =\frac{1}{s^{4}}\left(\frac{\left(-m^{4} \pi^{4} \lambda^{4}+\Omega^{2}-k_{w}\right)\left(\alpha s^{2}+\beta\right)}{s^{4}}+\frac{k_{P}\left(\alpha s^{2}+\beta\right)^{3}}{s^{12}}\right) \text {, } \\
& w_{1}=\frac{1}{6} x\left(\beta x^{2}+6 \alpha\right)+ \\
& +\frac{x^{5}\left(\begin{array}{l}
-259459200 \pi^{4} \beta \lambda^{4} m^{4} x^{2}+\beta^{3} k_{P} x^{10}-10897286400 \pi^{4} \alpha \lambda^{4} m^{4}+630 \alpha \beta^{2} k_{P} x^{8}+98280 \alpha^{2} \beta k_{P} x^{6} \\
+3603600 \alpha^{3} k_{P} x^{4}+259459200 \Omega^{2} \beta x^{2}-259459200 \beta k_{w} x^{2}+10897286400 \Omega^{2} \alpha-10897286400 \alpha k_{w}
\end{array}\right)}{1307674368000} .
\end{aligned}
$$

Using the definition of VPM, the analytical series solution is obtained.

$$
W(x)=\sum_{m=0}^{\infty} W_{m}(x)=W_{0}(x)+W_{1}(x)+W_{2}(x)+\ldots
$$

Table 1 provides parameters for validation of the hybrid method to confirm the accuracy of the results. First equation of the simultaneous equation obtained through introduction of parameters Table 1 to Eq. (45) to obtain values of the unknowns introduced into the boundary condition. 
Table 1. Parameters for validation of the model

\begin{tabular}{|c|c|c|c|c|}
\hline $\begin{array}{c}\text { Pasternak } \\
\text { foundation }\end{array}$ & Winkler foundation & Poisson ratio & Integer & Aspect ratio \\
\hline $\mathrm{Kw}$ & $\mathrm{Kp}$ & $v$ & $\mathrm{~m}$ & $\lambda$ \\
\hline 0 & 0 & 0.3 & 1 & 1 \\
\hline
\end{tabular}

$\psi_{11}^{(n)}(\Omega) w_{0}+\psi_{12}^{(n)}(\Omega) w_{2}=0$.

$\psi_{21}^{(n)}(\Omega) w_{0}+\psi_{22}^{(n)}(\Omega) w_{2}=0$.

The polynomials are represented as $\Psi_{11}, \Psi_{12}, \Psi_{21}$ and $\Psi_{22}$. Eq. (46) can be written in matrix form as:

$\left[\begin{array}{ll}\psi_{11}^{(n)}(\Omega) & \psi_{12}^{(n)}(\Omega) \\ \psi_{21}^{(n)}(\Omega) & \psi_{22}^{(n)}(\Omega)\end{array}\right]\left\{\begin{array}{l}w_{0} \\ w_{2}\end{array}\right\}=\left\{\begin{array}{l}0 \\ 0\end{array}\right\}$.

The following Characteristic determinant is obtained applying the non-trivial condition

$\left[\begin{array}{ll}\psi_{11}^{(n)}(\Omega) & \psi_{12}^{(n)}(\Omega) \\ \psi_{21}^{(n)}(\Omega) & \psi_{22}^{(n)}(\Omega)\end{array}\right]=0$.

Solving Eq. (48) gives the natural frequencies.

Solving the quadratic Eq. (48) gives the natural frequencies

$\Omega=11.89228774$.

Substitute the values of natural frequency obtained into Eq. (47)

$\left[\begin{array}{cc}\frac{41777}{12701} & \frac{24325}{28703} \\ -\frac{196444}{7691} & -\frac{119607}{18175}\end{array}\right]\left\{\begin{array}{l}\alpha \\ \beta\end{array}\right\}_{(1)}=\left\{\begin{array}{l}0 \\ 0\end{array}\right\}$.

Putting $\alpha=1$ and solving for $\beta$

$\left\{\begin{array}{l}\alpha \\ \beta\end{array}\right\}_{(1)}=\left\{\begin{array}{c}1 \\ -3.881269291\end{array}\right\}$.

Deflection solution of the governing equation gives;

$$
w(x)=\frac{x^{5}\left(-44326904170 x^{2}+479670396000\right)}{1307674368000}+\frac{1}{6} x\left(-\frac{40241 x^{2}}{10368}+6\right) .
$$

\section{Results and discussions}

The solution of Laplace transform and Variation parameter method is presented here. Table 2 presents comparisons of fundamental natural frequency results of the present study with that of the past works. It was observed from the Table 2 that, there are good agreements between the present study and the past results, while Table 3 shows effect of plate resting on elastic foundation. Figs. 2 and 3, show the fundamental modal shapes of the thin rectangular plate. Also, Figs. 4 and 5 show the variation 
Table 2. Showing validation of results

\begin{tabular}{|c|c|c|c|c|c|c|}
\hline $\begin{array}{c}\text { Edge Condition/ } \\
\begin{array}{c}\text { Dimensionless } \\
\text { Natural frequency }\end{array}\end{array}$ & \multicolumn{2}{|c|}{ Simply-supported (SS) } & \multicolumn{2}{c|}{$\begin{array}{c}\text { Simply supported- } \\
\text { Clamped (SC) }\end{array}$} & \multicolumn{2}{c|}{$\begin{array}{c}\text { Simply-supported-Free } \\
\text { (SF) }\end{array}$} \\
\cline { 2 - 8 } & Bambill et al [15] & Present & Leissa [16] & Present & Leissa [16] & Present \\
\hline$\Omega 1$ & 19.7392 & 19.7434 & 23.6463 & 23.6486 & 11.7195 & 11.7606 \\
\hline
\end{tabular}

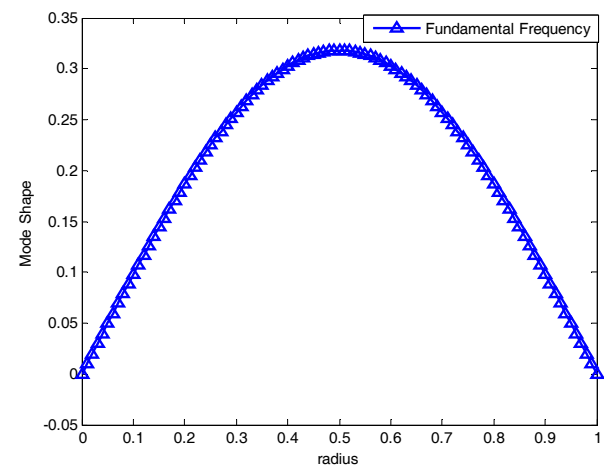

(a)

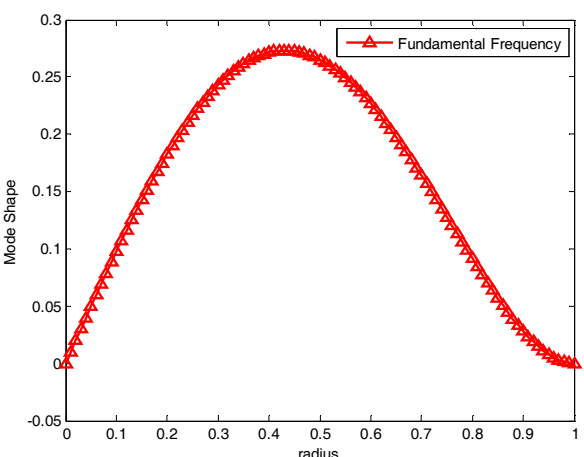

(b)

Fig. 2. Fundamental mode shapes of Simply Supported Condition at both edges and Simply Supported with Clamped edge

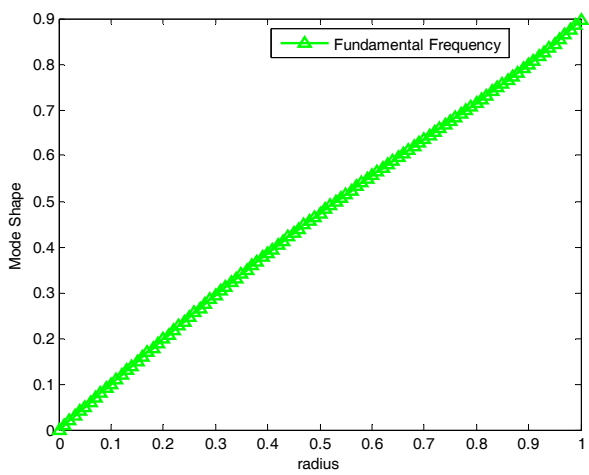

Fig. 3. Fundamental mode shapes of Simply Supported Condition at one edge and free at other edge

effects of foundation parameters and aspect ratio on natural frequency. It is observed that the natural frequency increases with increases in foundation parameters and aspect ratio. Variation of Combine effect of Winkler and Pasternak foundation also results into increases with natural frequency.

\subsection{Effect of foundation Parameter on natural frequency}

Figs. 4 and 5 illustrate the effects of foundation Parameter on natural frequency. It is clear from the Figures that the foundation parameter influences on natural frequency, increasing values of the foundation parameter has direct 1 effect on the natural frequency based on classical theory. Increasing stiffness results in increase in natural frequency 
Table 3.Variation of Aspect ratio and foundation coefficient

\begin{tabular}{|c|c|c|c|c|c|c|c|}
\hline \multirow{2}{*}{$\begin{array}{c}\text { Edge } \\
\text { Condition }\end{array}$} & \multirow{2}{*}{$\begin{array}{c}\text { Natural } \\
\text { frequency }\end{array}$} & \multicolumn{3}{|c|}{$\lambda=0.5$} & \multicolumn{3}{c|}{$\lambda=1.5$} \\
\cline { 3 - 8 } & & $\mathrm{k}_{\mathrm{w}}=10$ & $\mathrm{k}_{\mathrm{w}}=50$ & $\mathrm{k}_{\mathrm{w}}=100$ & $\mathrm{k}_{\mathrm{w}}=10$ & $\mathrm{k}_{\mathrm{w}}=50$ & $\mathrm{k}_{\mathrm{w}}=100$ \\
\hline $\mathrm{SS}$ & $\Omega 1$ & 12.7358 & 14.2198 & 15.8809 & 32.2317 & 32.8464 & 33.5989 \\
\hline $\mathrm{SC}$ & $\Omega 1$ & 17.6179 & 18.7187 & 20.0097 & 35.1935 & 35.7573 & 36.4497 \\
\hline $\mathrm{SF}$ & $\Omega 1$ & 5.1255 & 8.1407 & 10.7829 & 24.2175 & 25.0297 & 26.0093 \\
\hline
\end{tabular}

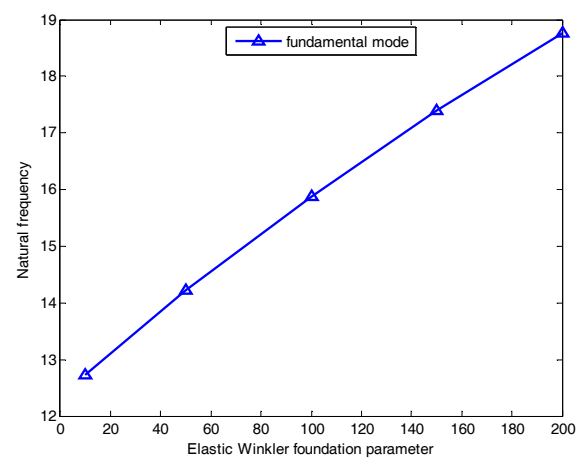

(a)

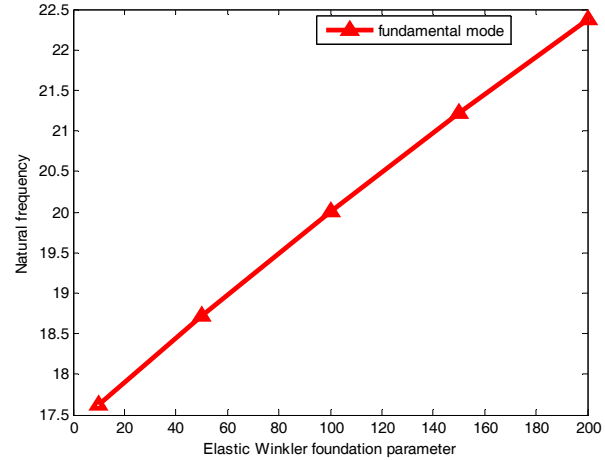

(b)

Fig. 4. Variation of foundation parameter on SS-edge and SC edge condition

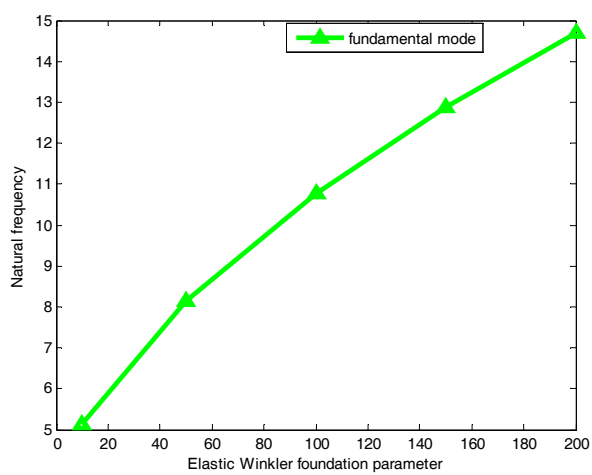

Fig. 5. Variation of foundation parameter on SF edge condition

\subsection{Effect of variation of aspect ratio on natural frequency}

According to Figs. 6 and 7 the aspect ratio influences on natural frequency. It is shown that, the natural frequency increases with the increase in aspect ratio. This is because, the aspect ratio here means variation in size of plate length divided by width. Increasing size of the plate increases the stiffness of the plate resulting into the plate being stiffer. It results in increasing the natural frequency of the plate.

\section{Conclusion}

In this study, the investigation of dynamic analysis of isotropic rectangular plates resting on Winkler and Pasternak foundations using Laplace transform and variation parameters method is 

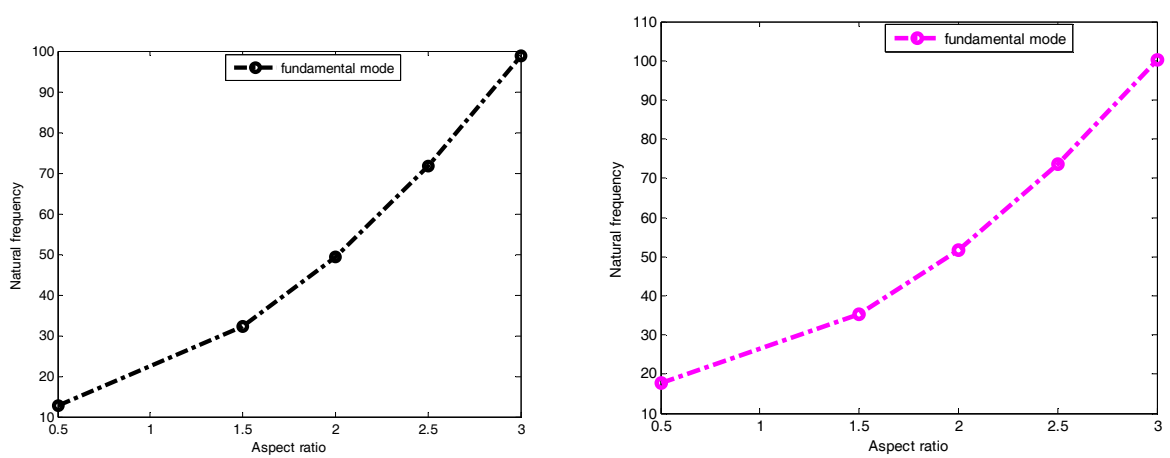

Fig. 6. Variation of Aspect ratio on SS and SC edge condition

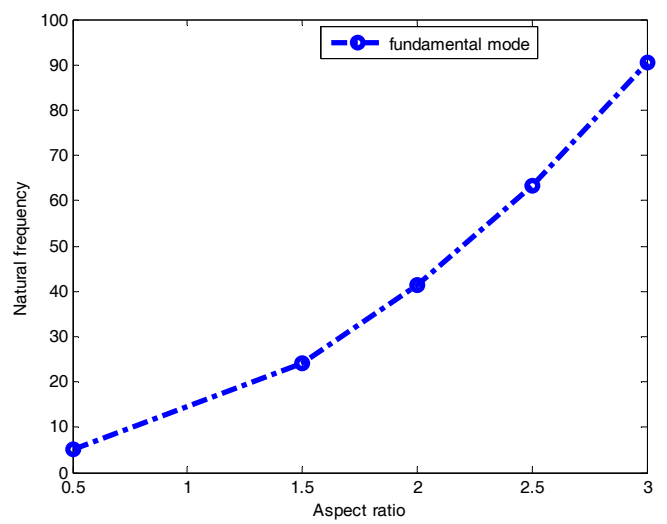

Fig. 7. Variation of Aspect ratio on SF edge condition

analyzed. The governing nonlinear partial differential equation is transformed to nonlinear ordinary differential equation by means of Galerkin method of separation. The nonlinear ordinary differential equations have been solved using Laplace transform and variation parameters. The accuracies of the obtained analytical solutions were ascertained with the results obtained by some other methods as presented in the past works. The obtained analytical solutions were used to examine the effects of foundation parameter and aspect ratio. Based on the parametric studies, the following observations were made:

1) Increases in elastic foundation parameter increases the natural frequency.

2) Increases in aspect ratio increases the natural frequency.

3) Increases in combine foundation parameters increases the natural frequency.

\section{Abbreviations: Nomenclature}

a: Length of the plate

b: Width of the plate

C: Clamped edge plate

E: Young's modulus

F: Free edge support 
S: Simply supported edge

$\frac{d}{d x}:$ Differential operator

w: Dynamic deflection

$\mathrm{X}$ : Space coordinate along the length of thin plate
Symbol
h: Plate thickness
$\rho$ : Mass density
D: Modulus of elasticity
$\Omega$ : Natural frequency
Conflicts of Interest

The authors declare that there are no conflicts of interest regarding the publication of this paper.

\section{Acknowledgments}

The authors express sincere appreciation to the University of Lagos, Nigeria, for providing material supports and good environment for this work.

\section{References}

[1] Sundara K.T., Raman P.V., Iyengar R. Free vibration of rectangular plate of arbitrary thickness, Journal of sound and vibration, 1977, 54(2), 8.

[2] Cheung Y., Kong J. The application of new finite strip to the free vibration of rectangular plate of varying complexity, Journal of sound and vibration, 1995, 181(2).

[3] Adhikari B., Singh B.N. Dynamic response of functionally graded plates resting on twoparameter elastic foundation model using quasi 3D theory, Mechanics Based Design of structures and Machines, 2019.

[4] Karasin A. Vibration of rectangular plates on elastic foundation by finite grid solution, International Journal of Mathematical and Computational Methods, 2016, 140-145.

[5] Zenkour A., Radwar A.F. Compressive study of functionally graded plate resting on WinklerPasternak foundation under various boundary conditions using hyperbolic shear deformation theory, Archives of Civil and Mechanical engineering, 2018, 18(2), 645-658.

[6] Vgor S., Moshe E.B. Semi-analytical modelling of cut-outs in rectangular plates with variable thickness-free vibration analysis, Applied Mathematical modelling-Elsevier, 2016, 1-18.

[7] Mustafa R.A., Ajetumobi M.O. On the solution of some problems using variation iteration method, International Journal of Mathematical Analysis and Optimization, 2018, 321-337.

[8] Attarnejad R., Shahba A., Semnam S.J. Application of differential transform in free vibration analysis of Timoshenko beam resting on two-parameters elastic foundation, Arabian Journal for science and engineering, 2010, 35(2), 135-146.

[9] Ghorbani A., Nadjfi J.S. He's homotopy perturbation method for calculating Adomian's polynomials, International Journal of Nonlinear Science and Numerical Simulation, 2007, 8(2), 229-332.

[10] Ma W.X., You Y. Solving the Korteweg-de Vries equation by its bilinear form:Wronskian solutions, Transactions of the American Mathematical Society, 2004, 357, 1753-1778. 
[11] Mohyud-Din S.T., Noor M.A., Noor K.I. Waheed A. Modified variation of parameters method for solving nonlinear boundary value problems, International Journal Modified Physics B, 2009.

[12] Noor M.A., Mohyud-Din S.T., Waheed A. Variation of parameters method for solving fifthorder boundary value problems, Applied Mathematics Inf. Sci., 2008, 2, 135-141.

[13] Chakraverty S. Vibration of Plate, London, CRC Press Taylor \& Francis Group, 2009.

[14] Leissa A.W. Vibration of Plates, Columbus, Ohio: Scientific and Technical information Division, Office of Technology Utlilization National Aeronautics and Space Adminstration, 1969.

[15] Bambill D.V., Rossit R.E., Laura P.A.A. Transverse vibration of an orthotropic rectangular plate of linearly varying thickness and with a free edge, Journal of Sound and Vibration, 2000, 235(3), 530-538.

[16] Leissa A.W. The free vibration of rectangular plates, Journal of Sound and Vibration, 1973, 31(3), 257-293. 